\title{
Insides and essences: Early understandings of the
} non-obvious*

\author{
SUSAN A. GELMAN \\ HENRY M. WELLMAN \\ University of Michigan
}

Received March 26, 1990, final revision accepted September 24, 1990

\begin{abstract}
Gelman, S.A., and Wellman, H.M., 1991. Insides and essences: Early understandings of the non-obvious. Cognition, 38: 213-244.

Insides and essences are both critical concepts for appreciating the importance of non-obvious entities: neither are observable, both contrast with external appearances. and both can be more important than external appearances. The present research examined understandings of insides and essences in 3- to 5year-old children. In Siudy 1, children were asked questions requiring them to think about both the insides and the outer appearances of a series of objects. In Study 2, children were tested on their understanding that insides are typically more important than outer surfaces for an object's identity and functioning. In Studies 3, 4, and 5, children were tested on their understanding of innate potential, a concept that reflects understanding of an inborn essence. Contrary to the traditional view of children as externalists (cf. Piaget, 195i), these studies demonstrate that by age 4 children have a firm grasp of the importance of both insides and essences. Even by age 3 children reason clearly about the insideoutside distinction. These results suggest that preschool children attend to nonobvious features and realize their privileged status. They may also indicate a more basic predisposition toward psychological essentialism in young children.
\end{abstract}

*This research was supported in part by NICHD grant HD-23378 and a Spencer Fellowship to S. Gelman and NICHD grant HD-22149 to H. Wellman. We are grateful to Catherine Givens for her assistance in Studies 1 and 2, and to Rebecca Stein and Michelle Wecksler for their assistance in Studies 3 and 5 . We trank Grant Gutheil for helpful comments and for conducting Study 4, and two anonymous reviewers for suggestions on an earlier manuscript. We also gratefully acknowledge the children, teachers, and staff of the following schools for their participation: Ann Arbor "Y", Gretchen's House, St. Luke's Day Nursery, and University of Michigan Children's Centers. Address for correspondence: Susan A. Gelman, Department of Psychology, 3433 Mason Hall, University of Michigan, Ann Arbor, MI 48109-1027, U.S.A. 


\section{Introduction}

In many ways adult cognition involves disregarding external appearances and instead penetrating to underlying realities, seeking deeper levels of analysis, and grasping (or inventing) non-obvious essences. This happens in everyday thought when we explain overt behaviors psychologically (by appealing to mental states, personality traits, and internal dynamics), when we categorize living kinds, such as mammals and birds, on the basis of non-obvious features (by appealing to their reproductive, genetic, and kinship relations), and when we go beyond observational appearances in countless other domains (acknowledging that the earth circles the sun, not vice versa, that fake diamonds are just glass, and so on). Attention to underlying, non-obvious realities also characterizes experts' knowledge in a broad range of fields, including scientific theories, map making, medical diagnosis, and impressionist art. Indeed, imagine the phenomenal world of an organism that regarded only external appearances - for example, an organism who understood people behavioristically, believed glass chips were diamonds, understood maps as merely decorated paper, or regarded having ‘easles as nothing more than wearing red spots.

One traditional and powerful view of young children, articulated in detail by Piaget (1951) and others, is that young children are remarkably like this hypothetical organism. They are, in other words, externalists. More precisely, children are described as incapable of reasoning about a broad cluster of understandings. On this view, until roughly age 6 or 7 children are artificialistic, assuming that natural or mechanical events are caused by people rather than by intrinsic or internal mechanisms (Piaget, 1929). They are thought to have difficulty reasoning about what they cannot see, such as internal mechanisms of the human body (Carey, 1985; Gellert, 1962); dreams, thoughts, and other mental states (Piaget, 1929); or non-obvious concepts that conflict with surface perceptions (Bruner, Olver, \& Greenfield, 1967). This child-as-externalist position suggests that a wide range of inabilities or conceptual confusions are interrelated and follow from the tendency to focus on the observable to the exclusion of other properties.

More recently, a number of findings in a variety of domains challenge this view, suggesting that children attend to non-obvious aspects of things well before school age (see Wellman \& Gelman, 1988, for review). For example, by 3 or 4 years of age children have a sensible understanding of the mind (Astington, Harris, \& Olson, 1988; Wellman, 1990), of the appearance-reality distinction (Flavell, Flavell, \& Green, 19९3), and of the importance of non-obvious properties for reasoning about categories (Gelman \& Markman, 1986; Gelman \& O'Reilly, 1988). It has further been suggested that such 
understandings may serve as a mechanism for cognitive growth.

In the present paper we examir.: children's understanding of the non-obvious, looking closely at children's beliefs concerning two inherently non-obvious aspects of things: insides and essences. Our goal is twofold: first, to provide further evidence that the externalist view mischaracterizes young children's cognition; and second, to articulate more precisely what kinds of knowledge young children do have.

\section{Insides and essences}

Concepts of insides and essences represent two distinct yet related understandings. Both insides and essences typically contrast with the outer appearance of an object. The insides of an item are the matter residing physically behind or under its outer layer (e.g., the bones, heart, and blood of a dog; the stuffing and wires of a chair). Insides are concrete and ultimately observable, yet typically remain unobserved. An essence is the unique, typically hidden property of an object that makes it what it is, without which it would have a different identity (e.g., the chemical composition of water, the DNA structure of an elephant). ${ }^{1}$ Essences generaily are never observed, and in fact may remain unknown (consider, for example, the essence of life, or the essential nature of humans). Locke (1894/1959) characterized essences this way: "Essence may be taken for the very being of anything, whereby it is what it is. And thus the real internal, but generally (in substances) unknown constitution of things, whereon their discoverable qualities depend may be called their essence" (p. 26).

Both insides and essences are difficult to define precisely. Do a dog's insides begin under the fur, under the skin, under the flesh, or indeed even interior to the skeletal framework? More troubling still, essences are typically unknown; those insensible parts or cores that enable or cause the sensible qualities of an object. Essences are often unspecifiable, and by their nature require an inference about some deeper organization or disposition. Nevertheless, adults certainly understand that objects have insides and outsides and can distinguish the two. Similarly, adults often distinguish essences from appearances and seem to believe that many objects have an essence. Medin and Ortony (1989), for example, suggest that adults "act as if their concepts contain essence placeholders" (p. 186) - they believe that things have an underlying reality or true nature that cannot be observed directly.

\footnotetext{
${ }^{1}$ We are not making a metaphysical claim about the true existence of essences in the world. Rather, we are referring to "psyychological essentialism" (Medin \& Ortony, 1989). or people"s beliefs that things have essences.
} 
For some objects, one kind of essence may be an internal part or substance (e.g., DNA structure); for other objects the essence may differ or remain unknown.

Although clearly different, insides and essences have a special affinity. On the one hand, for many objects insides are more essential to their identity or functioning than are outer appearances. On the other hand, many purported essences, such as the genetic code of an animal and the chemical structure of elements, are internal or compositional in nature and so neither external nor perceptible. Nonetheless, insides are not synonymous with essences; essential similarities may also take the form of behaviors, functions, parentage, psychological make-up, or even intangible qualities (e.g., a soul).

The inside-outside distinction seems a particularly promising vehicle for studying children's emerging ideas of the non-obvious. Internal parts (e.g., the seeds of an apple, the heart of a dog) are concretely present in everyday objects although intrinsically less obvious than outer surfaces. Children's grasp of the inside-outside distinction could be a stepping-stone to understanding a variety of non-obvious properties more generally. The insides of an object are often critical for its proper functioning (the spring of a watch) or for its appropriate use (the white and yolk of an egg). Even young children may grasp that internal parts or features can be more essential than outer coverings. Studies 1 and 2 focus on children's understanding of insides.

At first glance, essences would seem a more difficult concept than insides for children to grasp. Precise specification of a category essence certainly implies complex theoretical constructions. For example, an understanding of chemistry is required to realize that the essence of water is $\mathrm{H}_{2} \mathrm{O}$; an understanding of biology is required to posit that the essence of a tiger is its genetic structure. Nonetheless, as mentioned earlier, belief in some unspecified category essence may be frequent in adults and is possible even without such precise, scientific knowledge. Psychological essentialism - the psychological belief that certain kinds of objects or substances have something like a constitutive yet unknown essence - could thus also make an early developmental appearance. If it did, then such a belief could have important implications for children's subsequent knowledge acquisition and categorization. Studies 3,4 , and 5 of the present paper are designed to determine if and when children also hold the belief that categories encompass hidden essences.

\section{Study 1: The inside-outside distinction}

Recent work demonstrates that children are somewhat knowledgeable about the insides of familiar objects by age 3 years. If asked to report the contents of various objects they offer different answers for animate and inanimate 
things, typically reporting that animates have blood, bones, and internal organs (such as hearts or muscles), whereas inanimates have either nothing or have material such as cotton, paper, hair, or "hard stuff" (Gelman, 1987). By age 4 years children assume that members of a particular category are likely to have the same internal parts and substance as one another, claiming for example that all dogs have "the same kinds of stuff inside" (Gelman \& O'Reilly, 1988).

Although these demonstrations are informative, they provide only a preliminary picture of children's abilities. In particular, little work has examined whether children explicitly distinguish insides from outsides, and particularly whether they realize that insides can conflict with outer appearances. A critical component to understanding insides is to reaiize explicitly that they may. differ from outsides.

Understanding this "inside-outside distinction", as we will refer to it, seems analogous to understanding the appearance-reality distinction. Even an organism that consistently apprehends reality faces grave difficulties if it confuses reality with appearance, or vice versa (cf. Flavell et al., 1983). When reasoning about the appearance-reality distinction, focusing exclusively on reality is an error referred to as "intellectual realism" (e.g., reporting that a sponge painitied to resemble a rock not only is a sponge but also looks like a sponge). It is only when one can report that appearance and reality differ (e.g., "It's a sponge, but it looks like a rock") that one has a firm understanding of the distinction.

The only previous research shedding light on children's grasp of the insideoutside distinction was conducted by Gelman (1987). She asked 3-, 4-, and 5 -year-old children to describe both the insides and outsides of a range of animate and inanimate objects. She found that for animate things, subjects typically described insides and outsides differently (e.g., saying "skin" for the outside of an animal but "bones" for its inside).

In Study 1 we investigate children's understanding of the inside-outside distinction more directly. It is possible, for example, that in a task like R. Gelman's children simply respond to the inside and outside questions with common associates, without comparing these two levels directly. Therefore, in Study 1 we included sets of pictures in which appearances and internal properties were placed in direct conflict with one another (e.g., children had to reason about triads of pictures representing an orange, a very similar-looking orange balloon, and a lemon). These items can reveal whether children are capable of reflecting on both outer appearances and internal properties in the same task. Rather than simply describe the insides and outsides of objects taken one at a time, children were asked to match up two objects at a time in terms of either appearances or insides. In order to answer correctly about insides, children had to select two items that looked very different on 
the outside as having the same insides (e.g., they had to select the orange and the lemon as having the same insides, even though the orange much more clearly resembled the orange balloon).

\section{Method}

\section{Subjects}

Twenty-three 3 -year-olds $(3 ; 2$ to $4 ; 2$, mean age $3 ; 9)$ and 24 -year-olds $(4 ; 4$ to $5: 2$, mean age $4: 8$ ) participated. One additional 3-year-old was tested but did not complete the session. In addition, 10 adults participated in a pretest of the items (see below).

\section{Items}

Each child saw the six sets of items listed in Table 1. For each set, children saw three pictures at a time, consisting of one target picture and two comparison pictures. The sets were constructed so that appearances and category membership conflict. For example, on one item children saw a pig (target picture), a piggy bank, and a cow. The pig and the piggy bank look very similar, whereas the pig and the cow are both animals. As can be seen in Table 1, the target items were chosen to include two animals, two inanimate natural kinds (e.g., orange, nut), and two inanimate containers. All pictures were color photographs or realistic color drawings.

\section{Adult pretest}

The purpose of the pretest was to validate that the pairs of pictures selected to be perceptually similar were indeed viewed that way, at least by naive adults. Adults saw each of the six triads, one at a time, with the three pictures arranged in a triangle. For each triad they were asked to choose the two pictures that "looked most similar". Performance was consistent with our prudictions $90 \%$ of the time, which grcatly exceeds chance performance of $33 \%, t(9)=703.0, p<.0001$.

\section{Table 1. Items used in Study I}

$\begin{array}{lll}\text { Target } & \text { Same appearance } & \text { Same insides } \\ \text { pig } & \text { piggy bank } & \text { cow } \\ \text { hound dog } & \text { stuffed dog } & \text { sheep dog } \\ \text { orange } & \text { balloon } & \text { lemon } \\ \text { almond nut } & \text { rock } & \text { peanut } \\ \text { glass of milk } & \text { glass of orange juice } & \text { carton of milk } \\ \text { bowl of cereal } & \text { bowl of soup } & \text { box of cereal }\end{array}$




\section{Procedure}

Children were tested individually in a small room apart from their regular classroom. The session began with a brief warm-up designed to clarify the task and remind children to think about both insides and outsides. In this warm-up children saw a pitcher of water with a handle and were asked whether the handle was inside or outside of the pitcher, and whether the water was inside or outside of the pitcher. On rare occasions when a child answered one of these questions incorrectly, he or she was corrected and asked the questions again. All children answered correctly at this point.

The experimental session included a series of eight questions asked of each triad. The two focal questions required the child to match the target with one of the two comparison pictures: (1) Which comparison picture looks most like the target? (e.g., "Which of these looks most like the pig, the piggy bank or the cow?"); and (2) Which comparison picture has the same kinds of insides as the target? (e.g. "Which of these has the same kinds of insides as the pig, the piggy bank or the cow?"). Half the children were always asked the "looks like" question first; half were always asked the "insides" question first. In between the two focal questions, the "looks like" question and the "insides" question, children were asked to describe the insides and outsides of each picture in each triad (i.e., what do a pig, a piggy bank, and a cow "have inside" and "have outside").

\section{Results}

Each of children's choices on the focal "looks like" and "insides" questions were coded as either correct or incorrect, yielding a total score ranging from 0 to 6 per question, or 0 to 12 across both questions. When responses to both questions were combined to yield a single score (out of 12), children performed significantly above chance (a score of 6 , or $50 \%$ ) at both ages (3-yearolds: $M=6.96, t(22)=4.70, p<.0001 ; 4$-year-olds: $M=8.80, t(23)=5.94$, $p<.0001)$.

We then coded the number of same-category responses given to each question at each age (e.g., responses claiming that the pig and the cow - rather than the pig and the piggy bank - looked most alike or had the same insides). The results are shown in Table 2 . The data were analyzed by a 2 (age: 3 years, 4 years) $\times 2$ (question type: looks like, insides) repeated-measures analysis of variance. There was a significant main effect for question type, $F(1,45)=51.95, p<.0001$, as weil as a question type by age interaction, $F(1,45)=12.45, p<.001$. These results indicate that overall children at both ages appropriately distinguiched between insides and looks like probes, but the distinction became clearer with age. There were no other significant effects. 
Table 2. Study 1, mean number of same-category responses by age and question type (out of 6 total)

\begin{tabular}{lll} 
& Inside & Looks like \\
\hline Age 3 & $3.61^{*}$ & $2.65^{\mathrm{a}}$ \\
Age 4 & $4.17^{*}$ & $1.37^{* * 3}$
\end{tabular}

*Significantly different from chance, $p<.01$.

** Significantly different from chance, $p<.0001$.

${ }^{a}$ The difference between responses to the inside and lookslike questions was significant at $p<.05$.

Of particular interest in this study were children's errors. We classified them into three types, based on Flavell et al.'s (1983) work on the appearance-reality distinction. First, there were errors in which children relied too much on appearances, or "phenomenism" errors. Here, children said that objects that looked alike also had the same insides (e.g., the pig and the piggy bank). Second, there were errors in which children relied too much on category membership, or "realism" errors. Here, children said that the objects that had the same insides actually looked alike (e.g., the pig and the cow). Finally, children could show uninterpretable errors - answering incorrectly on both the insides and looks-like questions. As shown in Figure 1, children showed as many realism errors as phenomenism errors. In other words, children's errors did not result from simply focusing on perceptual similarity. Note that some of children's errors (particularly phenomenism errors) would be very reasonable to make if children lack particular knowledge about the objects in question. (For example, a child who does not know what is inside a piggy bank may assume that pigs and piggy banks are internally similar.) Thus, children's above-chance performance and their failure to give overwhelming numbers of phenomenism errors are all the more impressive.

\section{Descriptions of insides and outsides}

Children's descriptions of the insides and outsides of each picture were transcribed. For each triplet, we coded (1) whether the insides attributed to the two different kinds of things (e.g., pig and piggy bank) were different, (2) whether the insides attributed to the two things of the same kind (e.g., pig and cow) were different, and (3) whether the insides attributed to each target item (e.g., bones for the insides of the pig) were different than the outsides attributed to that item (e.g., skin for the outside of the pig). In order for the descriptions to count as different, subjects had to supply two distinct and specific descriptions. We did not include in this tally any trials on which 
Figure 1. Mean percentage of realism, phenomenism, and other errors in Study 1.

Error Analysis

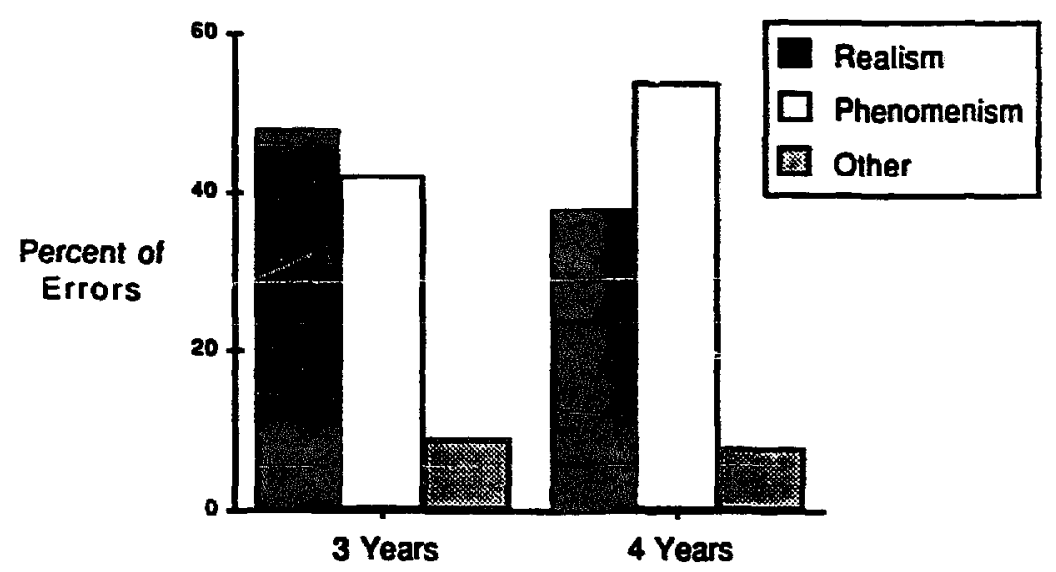

subjects said that they did not know what was inside or outside. A second person independently coded almost $20 \%$ of the items and agreed with the first coder on $90 \%$ of these decisions.

The purpose of this analysis was to provide converging evidence for the claim that children distinguish insides from outsides. Do children realize that the insides of objects can differ even when their surface appearances are strikingly similar, and that the insides and outsides of the same item differ? In one sense this is an easier task than the judgment task reported earlier, because children were asked to consider only one object at a time. The present task can provide additional useful information, however, because children were required to name particular internal contents. Whereas the judgment data tap children's knowledge that the insides differ, the descriptions can provide insigint into their beliefs about how the insides differ.

Table 3 presents the mean number of trials (out of 6 possible) on which children reported that: (1) the insides differed, for the different-insides pairs; (2) the insides differed, for the same-insides pairs; and (3) the insides differed from the outsides, for the target items. These data were analyzed by means of a 2 (age: 3 years, 4 years) $\times 3$ (comparison: insides different (insides-different pairs), insides different (insides-same pairs), insides versus outsides different (target items)) ANOVA. There was a main effect for age, $F(1,45)$ $=6.80, p<.02$, a main effect for comparison type, $F(2,90)=187.16, p<$ .00001 , and an age by comparison type interaction, $F(2,90)=5.72, p<.005$. At both ages, children's description of the insides of a single object typically 
differed from their descriptions of the outsides of that object. Moreover, their descriptions were much more likely to differ when describing the insides of different kinds of things (e.g., pig and piggy bank) than when describing the insides of the same kind of thing (e.g.. pig and cow). Finally, this last effect was slightly more pronounced in the older children.

One way of comparing these results to those from the judgment task is to say that the pictures that looked alike were typically described as having different insides. Children readily overlooked misleading perceptual information when describing the insides.

It is important to note in this analysis that children did not have to be accurate in order to appreciate differences appropriately. For example. a child could say that an orange balloon has orange air inside and an orange has orange juice inside, or that an orange has orange skin outside and orange babies inside, and still be credited with appropriately reporting that insides are different in these cases. Indeed many incorrect responses occurred (e.g., rocks have nothing inside, peanuts have skin outside, a stuffed dog has blood but no bones inside, a soup bowl has tiny bowls inside, a balloon has little balloons inside) and many uninformative ones occurred as well (lemons have lemony stuff outside, piggy banks have colors outside, everything has skin outside, a stuffed dog has stuff inside). These sorts of inaccuracies are important for demonstrating that children do not require knowledge of particular insides in order to appreciate a general inside-outside distinction.

Indeed, a fully knowledgeable and precise responder might report that even those items that are "the same kinds of things" do not have the same kinds of insides. For example, although pigs and cows are alike inside at a general level (both having blood and bones), they differ in the details of their physiology and anatomy (e.g., cows but not pigs have multiple stemachs). Accordingly, children's successful performance on this task does not require having detailed domain-specific knowledge and reflects instead a more general appreciation of hidden similarities and differences.

Table 3. Study 1. mean number of trials (out of 6 possible) on which subjects reported that the insides differed, as a function of pair type and age

\begin{tabular}{llll} 
Comparison type & \multicolumn{2}{c}{ 〈Age } \\
\cline { 2 - 3 } & 3 years & 4 years \\
\hline Insides for different-insides pair & 4.22 & 5.46 \\
Insides for same-insides pair & 2.04 & 2.25 \\
Insides vs. outsides for target object & 5.65 & 5.71 \\
\hline
\end{tabular}




\section{Discussion}

Altogether, there are two main findings from Study 1. First, children at both ages accurately distinguished insides from outsides, even though the task required them to consider both perspectives at once. In order to answer correctly subjects had to choose two items as having the same insides which, on a different part of the task, they judged as not looking alike. The second finding is that the children had some difficulty ignoring appearances to assess insides, particularly at age 3. Importantly, however, they also had some difficulty ignoring the insides to assess appearances. That is, when children made errors they showed no bias toward focusing on appearances; realism and phenomenism errors were equal even for 3-year-olds. What improves with age in this study is an ability to deal with conflict between insides and outer appearances, not a shift toward understanding insides at all. Young children readily attended to non-obvious internal similarities even though they conflicted with surface appearances.

\section{Study 2: Are insides essential?}

For adults an important aspect of understanding the inside-outside distinction is the realization that internal parts sometimes have a privileged status: they can be essential for defining an object or for its continued functionıng. At the very least, insides can be relatively more essential than outer surfaces. Recent studies by Keil (1989) suggest that children may not have this appreciation till early elementary school age. His method was to describe an object that changed in outer appearance only, and to ask whether that change constituted a change in kind. For example, a skunk was altered, through surgery and dye, to look like a raccoon while its insides remained unchanged. Preschoolers tended to report that the creature was now a raccoon; second graders reported that the animal was a skunk that only looked like a raccoon.

Keil's studies are valuable for demonstr . '. that, with development, children become better able to focus on less ou vous properties for judging identity. That is, success on Keil's task certainly seems to require an understanding of the importance of non-obvious insides, and as they get older children perform increasingly well on the task. However, failure on the task cannot be taken as demonstrating a clear lack of understanding, because the procedure does not seem sensitive for uncovering the abilities of the youngest age group.

One potential problem with the task concerns its reliance on questions about identity, and the relation of different criteria for determining identity. 
Both insides and outsides can figure into an object's identification and even into its conventionally agreed-upon identity, and it is often not clear how to resolve cases of discrepancy. For example, is a person who undergoes a convincing sex-change operation now a man, a woman. or some third kind of person? More generally. questions of identity (particularly borderline cases, such as the ship of Theseus; see Millikan, 1984) pose knotty philosophical conundrums that often have no clear intuitive (or psychological) solution. Insides can be essential to an object's identity without being the only relevant quality. Young children might know this and still fail Keil's task.

A related concern is that it seems more difficult to judge which of two identities (raccoon or skunk) applies after changes have been made, than to determine that such changes influence identity. It would be informative therefore to question children about items that posed less of an identity choice, for example to include animals in which the outsides were altered in such a way that they did not resemble another known species (e.g., a dog with no fur) and to ask whether identity was changed rather than what the identity was.

Note in addition that Keil's research failed to include items in which the animal's insides were altered but the outsicies remained the same (e.g., a dog with no blood or bones). This comparison could be crucial for gauging the relative importance of insides versus outsides for the young child. It is possible that children believe that any kind of change affects an object's identity, but that changing the insides is more important than changing the outsides.

\section{Method}

\section{Subjects}

Children of two age groups participated: 174 -year-olds $(4 ; 5$ to $4 ; 11$, mean age $4 ; 7)$ and 145 -year-olds $(5 ; 0$ to $6 ; 2$, mean age $5 ; 7)$. There were approximately equal numbers of girls and boys at each age. An additional two children (one at each age) were tested but completed only half the task, and so were not included in these analyses.

\section{Items and questions}

There were two kinds of test items: insides-relevant and insides-irrelevant. The insides-relevant items were ones for which the insides are critical to the identity and continued functioning of the object. Insides are not essential for all objects, so we selected items that would be clear-cut examples for adults. These included two animals (turtle, dog), two inanimate natural kinds (banana, egg), and three artifacts (book, pencil, car). As an example, the 
insides (yolk and white) of an egg are more critical than the shell for ordinary use of the item (e.g., cooking) or for its ordinary identification (without yolk and white it's "just a shell" rather than an egg). The insides-irrelevant items served as contrasts and included three containers (jar, toy box, and refrigerator), for which the insides (e.g., the jam in the jar) do not affect the object's identity and continued functioning. A realistic color drawing was used for each item.

We asked questions about both the insides and outsides of both the insidesrelevant and insides-irrelevant items. In this, we proposed to the child three sorts of transiormations and then asked the child whether each transformation of the item would change its identity and also an aspect of its ordinary functioning. More specifically, for each object children were asked to consider the following:

(a) Inside removal ("What if you take out the stuff inside of the dog, you know, the blood and bones and things like that and got rid of it and all you have left are the outsides?").

(b) Outside removal ("What if you take off the stuff outside of the dog, you know, the fur and got rid of it and all you have left are the insides?").

(c) Movement (e.g., "What if the dog stands up?"). This transformation served as a control to determine whether children have a bias to report that any change will result in a change of identity, given our task. If children have such a bias then the movement transformation can provide a baseline of correct responding against which to compare children's responses from the inside and outside removal questions.

All transformations are listed in Table 4. Following each transformation, children were asked two questions, always in the same order. One question concerned the identity of the transformed object (e.g., "Is it still a dog?"); a second concerned how the transformed object would function (e.g., "Can it still bark and eat dog food?").

Note in Table 4 that for the outsides removal we took off only the outermost veneer of the object (e.g., paint, fur). We did this because we wanted to propose clear contrasts between the object's insides and outsides. If we had proposed taking off a deeper layer of "outsides" we risked taking off some essential insides. In this study we were concerned with whether children consider insides essential; we were not concerned with the exact point at which children draw the line between insides and outsides. Therefore, the outside removals were not included to test children's understanding of outsides, but rather to contrast with inside removal and test whether in such a clear contrast children consider insides (interior to the outermost surface and appearance of the object) critical. 
Table 4. Items and transformations used in Study 2

\begin{tabular}{|c|c|c|c|}
\hline Item & Insides removal & Outsides removal & Movement \\
\hline \multicolumn{4}{|c|}{ Insides-relevant } \\
\hline turtle & blood & shell & put in box \\
\hline dog & blood and bones & fur & standis up \\
\hline egg & runny sturf & cgg shell & roll on table \\
\hline banana & white part & peel & turn upside-down \\
\hline car & motor & paint & turn around \\
\hline hook & pages & cover & turn over \\
\hline pencil & $\begin{array}{l}\text { black stuff } \\
\text { (lead'in middle) }\end{array}$ & paint & drop on table \\
\hline \multicolumn{4}{|l|}{ Comraine's } \\
\hline jar & food & $\begin{array}{l}\text { label (paper with } \\
\text { writing) }\end{array}$ & put in box \\
\hline toy hox & toys and games & paint & drag across room \\
\hline refrigerator & food and shelves & paint & $\begin{array}{l}\text { move to other side of } \\
\text { kitchen }\end{array}$ \\
\hline
\end{tabular}

\section{Procedure}

Children were tested individually in a small room apart from their regular classroom. The same warm-up was used as in Study 1. For each item, children first saw a picture of the standard (e.g., a dog) and were told its identity (e.g., "Here's a dog"), then were asked to consider the three transformations for that item, one at a time. For each transformation children were asked the identity and function questions. Thus, for each item, six questions were asked. The order of transformations (insides removal, outside removal, movement) was randomized across items and across children. For every transformation the two questions were asked in the same order: identity first, function second. Items were presented in one of two random orders, neither order beginning with a container. Approximately half the children at each age received each itcm order.

\section{Results}

We coded the proportion of trials on which each child said "no", that an item would no longer have the same identity or function as before. That is, the scores represent the proportion of trials that children affirmed that the object had changed identity or function. Our primary analyses concern the inside-removal versus outside-removal questions. 


\section{Inside-removal versus outside-removal questions}

The results are presented in Table 5. Two analyses were conducted: one concerning the identity questions and one concerning the function questions.

Identity. As evident in Table 5, correct responding to the identity questions for inside and outside removals averaged $73-69 \%$ for insides-relevant items and $78 \%$ for containers, collapsing across the insides-removal and outsides-removal questions. Wc conductcd a $2(\mathrm{agc}) \times 2$ (itcm typc: insidc-rclcvant items vs. containers) $\times 2$ (question type: inside removal vs. outside removal) ANOVA on subjects' percentage "no" responses. There were no significant effects for age. There was a significant main effect for item type, $F(1,29)=65.32, p<.0001$ and a significant main effect for question type, $F(1,29)=17.89, p<.0002$. However, both of these effects were subsumed under the expected significant interaction between item and question type, $F(1,29)=107.54, p<.0001$. As this finding indicates, children most often reported that identity changed when insides were removed from the insiderelevant items (e.g., when the insides of a turtle or egg were removed). On the relevant items, children considered insides more critical than outsides; on the containers, children considered both insides and outsides as irrelevant to the object's identity.

These findings for the insides-relevant items held up across all seven of the items tested. For example, correct performance on the insides-removal question (i.e., asserting that removing the insides does change identity) ranged from $81 \%$ for the egg to $65 \%$ for the car. Moreover, for each of the seven items, identity was judged to change more when the insides were removed than when the outsides were removed. Thus, the results appear to be widely generalizeable.

Table 5. Study 2, mean percentage of responses affirming that identity or function changes (numbers in parentheses indicate mean percent correct)

$\begin{array}{llll} & \text { Insides removal } & \text { Outsides removal } & \text { Movement } \\ \begin{array}{l}\text { Identity questions } \\ \text { Insides relevant }\end{array} & 72(72) & 35(65) & 12(88) \\ \text { Containers } & 17(83) & 28(72) & 10(90) \\ \begin{array}{l}\text { Function questions } \\ \text { Insides relevant }\end{array} & 92(92) & 29(71) & \\ \text { Containers } & 20(80) & 23(77) & 15(85) \\ \end{array}$


Function. As noted in the introduction, questions concerning identity might be especially difficult for adults as well as children. Therefore we also included questions about the objects' ordinary, characteristic functioning. As shown in Table 5, correct responding was marginally higher to function questions $(80 \%$ correct overall, $82 \%$ for inside-relevant items and $79 \%$ for containers) than to identity questions. More importantly, however, the pattern of results closely parallels the pattern from the identity question, reported above. Again we conducted a 2 (age) $\times 2$ (item type: inside-relevant items vs. containers) $\times 2$ (question type: inside removal vs. outside removal) ANOVA. There was a significant main effect for item type, $F(1,29)=115.04$, $p<.0001$ and a significant main effect for question type, $F(1,29)=77.33$, $p<.0001$. Again, these main effects must be interpreted in light of the significant item type by question type interaction, $F(1,29)=161.47, p<$ .0001 . These results demonstrate that children considered insides critical for object functioning, but only on inside-relevant items. On the containers, children considered both insides and outsides to be irrelevant.

Individual item analyses reveal that the advantage of insides held up on every one of the insides-relevant items. Across the seven items correct performance on the insides-removal question (i.e., asserting that removing the insides does change the item's characteristic functioning) ranged from $100 \%$ for the book to $87 \%$ for the turtle. And for each item, function was judged to change more when insides were removed than when outsides were removed. Again, this suggests that the results are broadly generalizeable.

\section{Movement questions}

We included the movement questions as a control, to assess whether and to what extent, in our task, children answer that any change affects the identity and functioning of an object. This seemed possible since our format was to propose a change to the child (e.g., the outsides are removed) and then to ask whether a change had resulted (e.g., "Is it still a ...?"). The movement transformations ask the child to consider patently irrelevant changes. The results are presented in Table 5. Overall, children were typically correct on these questions $(89 \%)$. However, there was a slight tendency to answer that identity and functioning change with movement changes. To assess whether this tendency emerged under certain conditions more than others, the results were analyzed by means of a 2 (age: 4-year-olds, 5-year-olds) $\times 2$ (question type: identity, function) $\times 2$ (item type: insides-relevant, containers) ANOVA. There were no significant effects. Overall, children knew that location changes were irrelevant to the identity and functioning for all items.

The slight bias to report that change has occurred cannot account for our 
primary results. Children claimed that inside removal changed identity and function much more often than they claimed that movement did ( $72 \mathrm{vs.} 12 \%$ for identity and 92 vs. $15 \%$ for function). More important still, in our prior analyses we compared children's judgments about insides removal with that for outsides; children were significantly more likely to say that insides removal changes identity than that outsides removal does. In sum, children understand insides as essential to an object's identity and functioning, and significantly more essential than the controls we included, namely, external parts and position.

\section{Discussion}

By age 4 years, children appreciate the special importance of insides for an object's identity and how it functions. These results contrast with Keil's (1989) findings, that children are misled by outer appearances until elementary school age. It may be that we were able to access an earlier understanding because we included no conflicting perceptual cues. All information about the hypothetical objects of interest were given by verbal descriptions. These may have allowed children to focus on the relevant features (insides versus outsides) without being caught up by misleading perceptual details.

A further difference between past work and the present study is that children were not simply asked to judge object identity. Even philosophers disagree as to what constitutes identity and what is sufficient to alter identity, and we had hypothesized that reliance on identity questions could have obscured children's knowledge in prior research. However, children in the present study considered insides critical to both identity and functioning. This constitutes a strong demonstration of young children's understanding that unseen insides can constitute privileged, even essential, qualities.

\section{Study 3: Innate potential of animals}

Study 2 focused on an overlap between insides and essences, demonstrating that even for preschoolers insides are considered essential to an object's identity and functioning. In tine final studies we focus more closely on whether children have a grasp of essences even when they are not necessarily internal or spatially localizable. As noted in the Introduction, essences come in many varieties and may even be unknown. Psychological essentialism represents a belief that there are essences; it does not necessarily entail accurate knowledge about particular essences.

We approach the issue of psychological essentialism by focusing initially 
on innate or intrinsic categcry potential. For many living kinds, an individual can have a certain intrinsic potential even before it manifests that potential in any visible way. For example, a tiger cub has the potential to grow into something large and fierce, even though when born it is small and helpless. To explain developmental changes of this sort, we as adults often appeal to something like an intrinsic category essence. In other words, all tigers have an underlying nature or essence that is responsible for how they grow. If children, too, believe that immature creatures have intrinsic potentials that are not yet visible but will become manifested over time, then this would constitute evidence of one kind of essentialism, the belief in an essential nature or a determining but non-manifest predisposition.

To test this notion, we conducted a study that can be thought of as a "nature-nurture" study. On each of a series of items, children were told about an immature being, a baby animal that was brought up in an environment more suited to a different species. The question is how children believe this animal will grow. Will it show as yet invisible, undeveloped potentialities intrinsic in its category membership, or will it instead display the properties associated with its environment of upbringing?

\section{Method}

\section{Subjects}

Fifty 4-year-olds participated. Twenty-five children were in the conflict condition, divided into older and younger groups (younger: $n=12,4 ; 0$ to $4 ; 7$, mean age $4 ; 3$; older: $n=13,4 ; 8$ to $5 ; 7$, mean age $5 ; 0)$. In addition, there were two control conditions; same upbringing control $(n=13,4 ; 2$ to $5 ; 0$, mean age $4 ; 4)$ and same category control $(n=12,3 ; 11$ to $4 ; 10$, mean age $4 ; 4)$. Subjects in these control conditions were approximately the same age as the younger group in the conflict condition, to make certain that even our youngest subjects could pass these controls.

\section{Items}

Five picture sets were used (see Table 6), all with realistic color drawings. Each set included a newborn animal of one species and a group of adult animals of another species (e.g., a newborn kangaroo and a group of adult goats). The newborn always had fewer prototypical features than the adults of its own species. For example, the baby kangaroo was hairless, pink, had closed-lidded eyes, and was curled into a small ball. For each set, the newborn animal picture was smaller than the picture of the adults. 
Table 6. Items used in Study 3

\begin{tabular}{|c|c|c|}
\hline Baby & Upbringing & Questions \\
\hline rabbit & monkeys & $\begin{array}{l}\text { long or short ears? } \\
\text { rather have carrots or bananas? }\end{array}$ \\
\hline tiger & horses & $\begin{array}{l}\text { striped or plain fur? } \\
\text { neigh or roar? }\end{array}$ \\
\hline cow & pigs & $\begin{array}{l}\text { straight or curly tail? } \\
\text { say "moo" or say "oink"? }\end{array}$ \\
\hline mouse & dogs & $\begin{array}{l}\text { round or floppy ears? } \\
\text { run away from or chase cats? }\end{array}$ \\
\hline kangaroo & goats & $\begin{array}{l}\text { have pouch or no pouch? } \\
\text { good at hopping or climbing? }\end{array}$ \\
\hline
\end{tabular}

\section{Procedure}

Children were tested individually in a small room. There were three conditions in this study, a conflict condition and two controls (same upbringing and same category controls). In the conflict condition, children first saw a picture of a baby animal which had few of the characteristics that the adult members of the species have. For example, they were shown a picture of a calf and were told that it was a cow. Children then learned that the baiby had been brought up by another species (e.g., Edith had been taken to a pig farm when she was a baby, was cared for by pigs, and never saw another cow). Children were shown a picture of the environment of rearing when it was mentioned (e.g., a picture of the pigs on the pig farm). Both pictures - of the baby and of the contrasting context of raising - were left in view. The baby animal was always reared in the company of adults of a different species.

For example, on the cow/pig item, children heard the following:

"Now I'm going to tell you about a cow named Edith. Look, here's a picture of Edith when she was a baby. Right after Edith was born, when she was just a tiny baby cow, she was taken to a farm that had pigs - lots of pigs. See, here are the pigs on the farm. The pigs took care of Edith. Edith grew up on the farm with all the pigs, and she never saw another cow."

For each item set, children were asked four questions. The first two questions were simple checks to make certain that children remembered the information we had given: What kind of animal was, for example, Editin, and who raised her? (In this example, the correct answers would be "a cow" and "pigs", respectively.) If a child answered either of these questions incorrectly 
or incompletely, he or she was corrected. The next two questions were focal for this study, and concerned how the animal would be after it grew up. One question concerned a mature physical feature (e.g.. "When Edith got to be a grown-up, what did her tail look like: was it straight or was it curly? Why?"). The other question concerned a mature behavior (e.g., "When Edith got to be a grown-up. what sound did she make: did she say 'moo' or did she say "oink"? Why?"). Importantly, neither of these questions could be answered by looking at the picture of the baby: for example, the picture of Edith did not include her tail. So children were asked about non-visible attributes of the target that would develop in the future. Children were encouraged to justify their answers to the last two questions for each item set.

Preceding the five item sets, all children first received an easy warm-up item concerning a baby bear that grew up with other bears. Children were asked two questions about the bear after it grew up: would it like honey or ketchup. and would it be brown or purple.

\section{Control conditions}

The two control conditions were included to ensure that the properties we used were ones that children of this age could answer correctly when there was no conflict - for example, we wanted to be certain that children would say that ordinarily cows say "moo" and have straight tails. In the same category control, children were presented with the picture of just the baby, and were told that it was raised in the cnvironment appropriate to that species (e.g., they saw Edith, a baby cow, and were told that she was raised by other cows). In the same upbringing control, children were presented with the picture of just the environment of raising, and were told about a baby appropriately raised in that environment (e.g., they were told about a hypothetical baby pig. Edith, and were shown the other pigs she was raised with). By including both control conditions, we could determine whether children knew not only that cows say "moo", but also that pigs say "oink" and do not say "moo".

In all three conditions, the order of items (except for the warm-up) was randomiy determined for each subject. The order of the choices (e.g., "Did she have a straight tail or a curly tail?" vs. "Did she have a curly tail or a straight tail?") were counterbalanced both within and between subjects. All sessions were audiotaped.

\section{Results}

We scored how often children answered in accord with innate potential or essence; the data are summarized in Table 7. Scores could range from 0 to 5 per subject and question type (behaviors vs. physical features). 
Table 7. Study 3. mean number of responses based on category membership (out of five), as a fumction of condition and age

$\begin{array}{lll}\text { Conditions } & \text { Behavior } & \text { Physical feature } \\ \text { Cattegory control } & +.50^{* *} & 4.18^{* *} \\ \text { Environment control } & +.23^{* *} & +.23^{* * *} \\ \text { Conflict condition } & 4.32^{* *} & 3.36^{*} \\ & & \\ * p<.01 . & & \\ * * p<.6161 . & & \end{array}$

\section{Control conditions}

The first analysis examined children's performance in the two control conditions to make certain that they could answer the questions accurately when there was no conflict, and that the behavior and physical feature questions were roughly equal in difficulty. The data were analyzed in a 2 (condition: category control, upbringing control) $\times 2$ (question type: behavior, physical feature) repeated-measures ANOVA. Results indicated no significant main effects or interactions due to either condition or question type (all $p s>.40$ ). Overall, children were correct a mean of 4.26 out of 5 items $(85 \%)$ in the control conditions, which is significantly above a chance expectation of $50 \%$ or $2.5, t(24)=12.68, p<.0001$. Thus, the properties used in this study are ones that subjects of this age are familiar with and attribute to the appropriate species.

\section{Conflict condition}

The primary results concern how children perform in the conflict condition when innate potential is in conflict with the environment of rearing. As shown in Table 7. children in the conflict condition nearly always answered on the basis of innate potential. For example, they said that a baby cow raised among pigs will grow up to say "moo" and have a straight tail. To examine the effects of age and question type more closely the results were analyzed by means of 2 (age: younger, older) $\times 2$ (question type: behavior, physical feature) repeated-measures ANOVA. There were no significant effects due to age. However, there was a main effect of question type, $F(1,23)=17.45$, $p<.0005$. Children relied more on innate potential when the question concerned a behavior (e.g., what noise a cow will make) than a physical feature (e.g., whether a cow will have a straight tail). However, performance was above chance $(50 \%$ correct or 2.5$)$ in both cells, $p<.01$. 


\section{Discussion}

The results of Study 3 suggest that children are essentialists, at least concerning how animals grow and mature. They assume that members of a category share something like an innate or intrinsic potential that will be realized even when an animal is reared by members of a different species.

The results of the conflict condition cannot be due to some bias simply to prefer some response alternatives (e.g., moo and straight tail) over others. In the same upbringing control, when children were shown just the picture of the rearing environment (e.g.. pigs) and were asked about a baby raised in that environment, they appropriately predicted that that baby would, in this example, oink and have a curly tail after it grew up. More generally, in the control conditions children chose either alternative, as appropriate.

A deeper issue concerns whether children's answers reveal an understanding of non-manifest pctential, or whether they simply reflect category associations (e.g., because the experimenter called the baby a kangaroo, it must hop and have a pouch). One piece of evidence against this latter interpretation is that children's answers differed according to the question type - behavior or physical feature. If children simply report category features or associations, they should do so equally for the two types of questions, but they did not. Children were more likely to grant the baby species-typical behaviors than species-typical physical features when it grew up, thus demonstrating that they considered each question separately and did not simply assume that the animals would have the properties normally associated with their names. We pursue this issue further in Study 4.

\section{Study 4: Inborn properties of animals}

In Study 4, children were asked which properties the infant animals of Study 3 had when they were babies. If children tend to presume that babies do not yet have their adult features, that would support our interpretation of the answers in Study 3 in two ways. First, it would provide converging evidence that children do not answer just by reporting category associations. Second, it would indicate that children in Study 3 correctly expected properties to develop that were not even yet present in the baby animals of the study.

\section{Method}

\section{Subjects}

Twelve children ranging in age from $3 ; 10$ to $4 ; 3$ participated (mean age $4 ; 1)$. Again we sampled younger 4-year-olds to be sure the data would represent even the youngest children tested in Study 3. 


\section{Items}

Each child was asked about the five baby animals used in Study 3 (see Table 6). For each, they were asked about four properties, the physical and behavioral features used in Study 3 (see Table 6) and also two new sorts of properties: inherent and impossible. Inherent and impossible properties serve as comparison items - the first are properties that all baby animals of the sort we included have from birth (e.g., legs, nose); the second are properties that members of these species never have (e.g., wings).

\section{Procedure}

For each item, the experimenter showed the picture of the infant (from Study 3) with no specified environment. Its proper name and species were identified, as in Study 3. Then children were asked the species name (as a memory check), followed by the four questions in random order. For example, on one item children were asked whether Edith (a cow) says moo (behavioral property), has a straight tail (physical property), has eyes (inherent property), and has fins (impossible property). Each question was a yes-no question, e.g., "Does this baby kangaroo have a pouch?” The order of items was randomized separately for each subject.

\section{Results and discussion}

Children attributed the behavioral properties to infant animals $87 \%$ of the time; they attributed the physical features only $40 \%$ of the time, $t(11)=6.20$, $p<.0001$. Both kinds of properties were attributed more often than the impossible ones (mean of $7 \%$ ), both $p s<.005$, but only the physical features were attributed less than the inherent ones (mean of $88 \%), t(11)=7.73$, $p<.0001$. That impossible properties were rarely if ever attributed to the infants shows that children's answers do not just reflect a response tendency to answer "yes".

Note that in this study children attributed specified physical features to infant animals only $40 \%$ of the time, whereas in Study 3 they attributed the se same features to the same animal, when it grew up, $67 \%$ of the time, $t(35)$ $=2.67, p<.02$. This result provides critical evidence that children are not just reporting category associations. Physical features that are typically attributed to the adult are typically not attributed to the infant. It is striking that subjects anticipate that properties not currently possessed by the infants will inevitably develop, and will do so even in an environment of upbringing encompassing very different appearances. This is precisely the sort of belief that is consistent with an intrinsic potential or category essence. The final point of interest is that the behaviors we used in Study 3 were seen as applying 
to category members even as infants, and were thought to apply just as frequently as inherent body parts (such as eyes or tails). We cannot explain this difference between behaviors and physical features, but the impressive result with regard to physical features remains.

\section{Study 5: Innate potential of seeds}

One potential difficulty with Study 3 was that, in order to specify the innate nature of the animals, each animal was identified as a member of a certain species (e.g.. children were told that Edith was a cow). This sort of species identification seems to imply an unchanging category membership which could bias children to attend to and report category associates (e.g., since cows have straight tails and say "moo", then so does Edith). It now seems unlikely that such an alternative explanation could account fully for the results, given the findings of Study 4. Nonetheless, Study 5 was designed in part to provide further evidence about this issue. In addition, we wished to extend our results beyond the domain of animals.

The format of Study 5 was the same as Study 3, except that the questions concerned seeds instead of baby animals. There are several advantages of this procedure. One can specify the nature and hence the innate potential of a seed (e.g., a seed that came from an apple) without giving it an unchanging category membership (i.e., an apple). Furthermore, a seed looks nothing like the mature plant or fruit it eventually becomes, in contrast to infant animals, which share some perceptual features with their mature kin. A seed that came from an apple is not an apple or an apple tree, nor does it resemble an apple or apple tree.

\section{Method}

\section{Subjects}

Similar to Study 3, 25 4-year-olds participated, divided into two groups: a younger group ( $n=12,4 ; 2$ to $4 ; 7$, mean age $4 ; 4)$ and an older group $(n=$ 13, $4: 9$ to $5 ; 4$, mean age $5 ; 1)$.

\section{Items}

Seven sets of items were included (see Table 8). Each set included a seed of one species and a plant or set of plants of another species (e.g., an apple seed and a pot of flowers). All items were presented as photographs, primarily in color. 
Table 8. Items used in Study 5

Seed
seed from apple
seed from watermelon
seed from lemon
seed from flower
seed from rose
seed from grape
pit from peach

Environment
flower pot
corn field
orange trees
strawberries
dandelions
coconut trees
plum trees

\author{
Question \\ apple or flower? \\ watermelon or corn? \\ lemon tree or orange tree? \\ flower or strawberry? \\ rose or dandelion? \\ grapes or coconut tree? \\ peach tree or plum tree?
}

\section{Procedure}

Children were tested individually in a small room. The session began with an easy warm-up question concerning a seed that came from a grapefruit and was planted with grapefruit trees. The remaining items posed a conflict between the innate potential of the seed and the environment in which it grew. For example, children saw a seed that came from an apple and was planted with flowers in a flowerpot. All questions concerned object identity (e.g., "When that seed grew, what popped up out of the ground, was it an apple tree or a flower?"). To imply unchanging category memberships as little as possible, the identity of the seed was never explicitly stated (e.g., an apple seed), but we referred only to "a seed that came from an apple".

Here is an example of the exact wording that children heard: "This seed came from a watermelon. A girl named Jennifer took this seed out of the watermelon. Then she planted the seed in a cornfield. See, here's the cornfield". In the pretest, we additionally said that the child "watered that place and made sure it got lots of sunshine, and the seed grew and grew. Now I'm going to ask you some questions".

The order of items (except for the warm-up) was randomly determined for each subject. The choices (e.g., "Was it an apple tree or a flower?" vs. "Was it a flower or an apple tree?") were presented in counterbalanced crder both within and between subjects.

\section{Results and discussion}

We scored how often children answered in accord with innate potential. Scores could range from 0 to 7 per subject. Given the two-choice answers, chance responding would be $50 \%$ or 3.50 . The primary result is that there was a significant difference in performance between the two age groups, $t(23)$ 
$=1.90, p<.05$, one-tailed. The older children, as in the previous study, answered overwhelmingly on the basis of innate potential $(M=6.0$ out of 7 correct, $t(12)=6.657, p<.0001$ ). Only one child in this age group (out of 13) answered below the chance level of 3.5 items correct; indeed, over half of these children performed perfectly. In contrast, the younger children as a group performed at chance levels $(M=4.17, t(11)=0.725$, n.s. $)$.

Although the younger children did not score above chance, they did not appear to be simply guessing. When individual response patterns were examined, we found that all 12 of the younger children answered consistently throughout the task. Specifically, seven children $(58 \%)$ were correct on every item or all but one (out of 7 ), and five children (42\%) were in error on every item or all but one (out of 7).

There are two points to make from this analysis. First, it is noteworthy that more than half the younger children consistently based their answers on innate potential on this particular task. The seeds as depicted were completely unrelated to any mature exemplar (e.g., the seed from an apple in no way looked like an apple or an apple tree). To the contrary, the only visible exemplars were those of the environment (e.g.. the flower plant was visible, but not an apple tree). Thus, in comparison to Study 3 , an environment-based response in this study would seem even more compelling. The fact that half the younger 4-year-olds and almost all the older 4-year-olds could ignore the salient environmental cues and answer on the basis of origins is significant.

The second point is that the younger children's bimodal pattern of responding suggests that around this age a change is taking place enabiing children to advance from consistent errors to a basically correct understanding. Although we can only speculate as to what is changing during this period, we suggest that children may be learning about the nature of seeds. In particular, it seems likely that children are learning that seeds are the immature versions of plants - that seeds are the plant "babies", so to speak. Once children grasp that critical fact, then their understanding of innate potential can be applied to seeds as well as to young animals. Until that point, children may misconstrue the relation between seeds and plants (e.g. , they may believe that seeds are plant food, or may simply know that seeds are found inside of plants), and so would have no reason to answer based on the seed identity.

The primary finding, therefore, is that in a very different domain (seeds versus animal babies) and in a task where an even firmer grasp of innate essences seems to be required to generate correct responses, 4-year-olds provided converging evidence of an understanding of non-visible, as-yet-undeveloped intrinsic potential.

One question these last three studies raise is when children can be said to possess biological concepts, for example an understanding of biological prop- 
erties of animals beyond a physical conception of their bodies and a psychological conception of their behaviors. The present findings suggest that children may have sensible biological understandings by age 4 years (see also Keil, 1989). Most strikingly, children's appreciation of intrinsic properties (demonstrated in Studies 3 and 5) could be considered to reflect an initial understanding of something like genetics. In contrast, Carey $(1985,1988)$ argued that children do not initially understand biological concepts as biological, in the adult sense, but rather misunderstand such concepts physically or psychologically. For example, preschoolers consider "babies" to be behaviorally limited versions of bigger animals, rather than their offspring. It may be that there are important beginnings of genuinely biological knowledge during this preschool period. Our findings are consistent with such a possibility but do not test it directly.

\section{General discussion}

The results from all five studies demonstrate that preschool children are not externalists, in contrast to the traditional view that their thinking is limited to phenomenal qualities. Instead, young children show an impressive ability to penetrate beneath surface appearances. These findings extend recent research showing that young children can sensibly describe the concrete insides of objects (Gelman, 1987) and expect categories to include features beyond those that are immediately perceptible (Gelman \& Markman, 1986). Beyond this, we have shown that young children distinguish insides of objects from their outsides, even when the two conflict, and believe that insides can be. more essential to an object's functioning and identity. Moreover, we provide evidence for an early understanding of innate potential, whereby immature living things are thought to possess a native essence that influences the nature of visible attributes, of non-visible attributes, and even of attributes not yet present in any form.

Throughout the paper we have introduced several related notions, including not only insides and essences, but also innate potential, inborn features, and intrinsic characteristics. At this point we wish to clarify how these concepts interrelate, and to what extent the present studies provide evidence for each. To undertake this discussion it seems useful to focus momentarily on living kinds (e.g., tigers) which have internal, inborn, and intrinsic features (see also Gelman \& Kremer, in press). "Internal" features are those that are on the inside of the organism, as we discussed in the Introduction. By "inborn" we mean properties that are possessed at birth either congenitally or genetically (e.g., the whiskers of a tiger). "Intrinsic" properties are not neces- 
sarily apparent at birth but are typical of adults and so typically acquired during an organism's lifetime (e.g.. tigers are intrinsically large and fierce, but are not actually large and fierce at birth). Thus, intrinsic properties are part of the innate potential of the organism, although the features themselves are often not inborn. These distinctions are not scientific ones, but rather part of our adult commonsense understanding. Commonsensically, internal, inborn, and intrinsic properties are separable notions. An internal feature (c.g., the defective heart of a tiger) may be neither intrinsic nor inborn: and, as just mentioned, intrinsic features (fierceness for tigers) need not be either inborn or internal in any literal, spatial sense. Internal, inborn, and intrinsic features can all bi non-obvious and in some sense "essential".

The present studies examined children's understanding that internal and intrinsic properties exist and are essential. With regard to children's understanding that non-obvious properties exist, we tested first whether preschoolers understood that objects could have insides quite different from their obvious outsides. Three- and 4-year-olds know this. We tested second whether children understood that living things - animals and seeds - could have intrinsic properties that are not inborn. Four-year-old children understand that babies and seeds have intrinsic properties - ones that are not apparent at birth but that inevitably manifest themselves over time. This, too, shows an appreciation for the primacy of non-obvious qualities.

Beyond testing children's understanding of the presence of non-obvious properties, we tested whether children consider them essential in the sense of specially important. We showed, first, that 4-year-olds understand that insides are often critical to an object's identity and functioning. We showed, second, that 4-year-olds understand that essential aspects of an item's identity (e.g., whether it will be a watermelon or corn, whether it will have the physical features of a kangaroo or a goat) can be completely non-obvious before it matures.

In addition to what they reveal about the conceptual understandings of 4-year-olds, the present findings have implications for two interrelated issues: the course of development, and the concept of psychological essentialism.

\section{Course of development}

Although our data concern mostly 4-year-olds, an intermediate preschool age tested in all four studies, we also provide some initial developmental findings. Before the fourth birthday, children have a clear albeit imperfect grasp of the inside-outside distinction (Study 1). They realize that such a distinction exists, and they can reflect on it even when insides directly conflict with outside appearances. The distinction may serve as a concrete precursor to the 
more refined understanding of insides and essences apparent in the older children.

Beyond the fourth birthday understanding in this area appears to be in part knowledge-dependent. Children's grasp of essences is partly limited by their knowledge of specific classes of objects. In particular, note that children appreciate the innate potential of animal babies at an earlier age than they appreciate the innate potential of plant seeds (Studies 3 and 5). Similarly, children`s grasp of the privileged nature of insides (Study 2) rests on specific knowledge of the distinction between containers and insides-relevant items. Thus, children's understanding of insides and essences can only be revealed when they have some pertinent knowledge about the object in question (e.g., whether or not it is a container, or the nature of its developmental stages).

Nonetheless, the range of items, categories, and tasks used in the present studies document that children's grasp of insides and essences has significant generality. Our findings clearly demonstrate an early disposition to expect insides and outsides to differ (at least for relatively complexly structured items like turtles and eggs, if not rocks and water), and to expect some objects to have essence-like qualities. For example, although 3- and 4-yearolds are by no means accurate at identifying the specific insides of even common objects such as oranges and dogs (Study 1), they firmly grasp that insides and outsides differ. Thus, children may have a general presumption that insides and essences exist, before they have much domain-specific knowledge about an item. We turn to this issue next.

\section{Psychological essentialism}

These findings stand on their own as demonstrating a grasp of the presence and importance of internal and intrinsic features by quite young children. Beyond this, however, the findings raise the question of whether or to what extent young children might not also be psychological essentialists.

Recently Medin (1989) has proposed that adults' concepts are framed by what he calls psychological essentialism (pp. 1476-1477):

The main ideas are as follows: People act as if things (e.g., objects) have essences or underlying natures that make them the thing that they are. Furthermore, the essence constrains or generates properties that may vary in their centrality. ...

It is important to note that psychological essentialism refers not to how the world is but rather to how people approach the world. Wastebaskets probably have no true essence, although we may act as if they do. Both social and psychodiagnostic categories are at least partially culture specific and may have weak if any metaphysical underpinnings (see also Morey \& McNamara, 1987). 
If psychological essentialism is bad metaphysics, why should people act as if things had essences? The reason is that it may prove to be good epistemology. One could say that people adopt an essentialist heuristic.

The notion of an essence is the hypothesis that objects possess constitutive natures that make them what they are, that such an underlying nature is distinct from but responsible for more obvious external features. Having stripes is not essential to being a tiger, but it may be the direct consequence of having a tiger essence. Positing that there are essences does not mean identifying what those essences are; in fact, essences are typically hidden and unknown.

The notion of an essence underlying an object's identity and character has been discredited in both philosophy and biology (Dupre, 1986; Mayr, 1988). But Medin's claim is that it remains a viable psychological phenomenon that people tend to believe that objects have essences, even though that belief may be faulty. Medin argues that describing adults as psychological essentialists accounts for much of their performance on categorization tasks. Essentialism is a powerfully useful psychological disposition that directs adult induction and knowledge acquisition (including the sorts of hypotheses we entertain and attempt to confirm). Medin suggests that such an essentialist disposition constrains our sense of similarity and can even have a revolutionizing influence on it.

It may seem premature to ask when and to what extent children become essentialists when it is still unclear whether adults arc. But we raise the question because psychological essentialism seems to be a plausible candidate for an important cognitive predisposition. Medin's arguments about its usefulness as a disposition in adult cognition can be extended to argue for the usefulness of such a presumption in knowledge acquisition, induction, and concept building in development.

That is, we propose that something like an essentialistic disposition could propel knowledge acquisition and shape concept representation early in development - not just at the end. Consider children's understanding of insides as revealed in the present studies. Why would such young children have a clear and distinct understanding that the insides of such varied things as pencils, turtles, and cars differ from their outsides? Although children may have considerable experience with these objects (e.g., having discovered that pencils make lines, can be sharpened if broken, etc.; that turtles have shells, walk slowly, etc.) that sort of everyday experience would not clearly yield an early understanding of their insides, nor an understanding that the insides are crucial to object functioning and identity. This sort of understanding of insides would be less mysterious, however, if children - like adults - are predisposed to believe that insides are different from outsides (see also Gelman, 1987), 
and that insides are essential to an object's identity and functioning. Children's early grasp of the critical nature of insides is consistent with the view that early in the process of knowledge acquisition children are psychological essentialists. An essentialist disposition could help account for the burgeoning evidence that even young children construct considerable knowledge about the non-obvious (Wellman \& Gelman, 1988), distinguish reality and appearances (Flavell et al., 1983), and form theories to organize and go beyond phenomenal observations (Carey, 1985; Wcllman, 1990).

We believe that psychological essentialism is an attractive possibility for such a basic developmental cognition, though of course the present data do not provide a direct test. Our data simply document an early and impressive understanding of insides and essences. This leaves open the question of whether children's knowledge, demonstrated here, is derived from accumulated past kitowledge, or whether instead manifests a belief brought to the task of acquiring knowledge. On the one hand, it is possible that children are acquiring numerous particular pieces of information about insides and essences - such as that pencils have lead inside, dogs have bones inside, apple trees are inherent in apple seeds, adult tiger behavior is intrinsic in tiger cubs. That is, a disposition toward essentialism in adults and, when it becomes present, in children may be the result of an accumulation of particular, acquired essentialistic beliefs of the sort studied here. If so, then the importance of the present findings is that they reveal the building blocks of an important adult acquisition.

On the other hand. something like psychological essentialism may be an early, basic cognitive predisposition revealed in (rather than built upon) young children's early understanding of insides and innate potentials. If so, then findings such as ours might have an even greater developmental significance, because such a basic disposition would have formative consequences.

We favor this second alternative, because in the present studies children seem prone to believe that insides are important even when knowing little about the insides in question. They also seem prone to believe that babies (or seeds) may have intrinsic properties even when knowing little about specific babies or seeds. Either alternative, however - that something like psychological essentialism emerges developmentally or that it frames knowledge acquisition developmentally - further underlines the importance of research on children's early developing notions of insides and essences. 


\section{References}

Astington. J.W.. Harris. P.L., \& Olson. D.R. (1988). Developing theories of mind. New York: Cambridge University Press.

Bruner. J.S.. Olver. R.R.. \& Greenfield. P.M. (1967). Studies in cognitive grousth. New York: Wiley.

Carey. S. (1985). Concepnual change in childhood. Caminiuge. MA: MIT Press.

Carey. S. (1988). Conceptual differences between children and adults. Mind and Language. 3. 167-181.

Dupre. J. (1986). Sex, gender, and essence. In P.A. French. T.E. Uehling Jr.. \& H.K. Wettstein (Eds.). Midwest Studies in Philosophy. XT. Studies in Essentialism (pp. H1-457). Minneapolis: University of Minnesota Press.

Flavell. J.H. (1977). Cognitive development. Englewood Cliffs. NJ: Prentice-Hall.

Flavell. J.H.. Flavell. E.R.. \& Green. F.L. (1983). Development of the appearance-reality distinction. Cognitive Psychology. 15, 95-120.

Gellert. E. (1962). Children's conceptions of the content and functions of the human body. Genetic Psychology Monographs, 65, $291-411$.

Gelman. R. (1987. August). Cognitive developmens: Principles guide learning and contribute to concephal coherence. Invited Address to Division 1. American Psychological Association. New York.

Gelman. S.A.. \& Kremer. K.E. (in press). Understanding natural cause: Children's explanations of how objects and their properties originate. Child Developmem.

Gelman. S.A.. \& Markman. E.M. (1986). Categories and induction in young children. Cognition, 23. $183-209$.

Geiman. 5.A., O Geiiy. A. 1 w. (1988). Chiidren's inductive inferences within superordinate categuries: The role of language and category structure. Child Developmem. 59. 876-887.

Keil. F.C. (1989). Concepts, kinds, and cognitive development. Cambridge. MA: MIT Press.

Locke. J. (1894/1959). An essay concerning human,understanding. Vol. 2. New York. NY: Dover.

Mayr. E. (1988). Toward a new philosophy of hiology. Cambridge. MA: Harvard University Press.

Medin. D.L. (1989). Concepts and conceptual structure. American Psychologist. 44. 1469-1481.

Medin. D., \& Ortony. A. (1989). Comments on Part I: Psychological essentialism. In S. Vosniadou \& A. Ortony (Eds.). Similarity and analogical reasoning (pp. 179-195). Cambridge. UK: Cambridge University Press.

Millikan. R.G. (1984). Language, thought, and other biological categories. Cambridge. MA: MIT Press.

Morey, L.C. \& McNamar.. T.P. (1987). On the definitions, diagnosis. and DSM-III. Journal of Abnormal Psychology, 96, 283-205.

Piaget. J. (1929). The child's conception of the world. London: Routledge and Kegan Paul.

Piaget. J. (1951). Plays, dreams, and imitation in childhood. New York: Norton.

Putnam, H. (1977). Is semantics possible? In S.P. Schwartz (Ed.). Naming, necessity, and natural kinds (pp. 102-118). Ithaca. NY: Cornell University Press.

Sugarman. S. (1987). Piager's construction of the child's reality. New York: Cambridge University Press.

Wellman. H.M. (1990). The child's theory of mind. Cambridge. MA: MIT Press.

Wellman, H. \& Gelman. S.A. (1988). Children's understanding of the nonobvious. In R.J. Sternberg (Ed.). Advances in the psychology of human intelligence (Vol. 4, pp. 99-135). Hillsdale. NJ: Erlbaum. 